\title{
Sensitization Reaction of Oxime Type Photoacid Generator
}

\author{
Shigeru Takahara, Shota Suzuki, Tomoaki Tsumita, \\ Xavier Allonas, ${ }^{\ddagger}$ Jean-Pierre Fouassier ${ }^{\ddagger}$ and Tsuguo Yamaoka \\ Graduate School of Advanced Integration Science, Chiba University, \\ 1-33 Yayoicho, Inage-ku, Chiba 263-8522, Japan \\ ${ }^{\ddagger}$ Department of Photochemistry, Université de haute Alsace, \\ 3 rue Alfled Werner, 68093, Mulhouse, France
}

\begin{abstract}
Pyrromethene dye/oxime type of photoacid generator (PAG) photoinitiating system based on the singlet electron transfer mechanism was found. The photoacid generation quantum yield $\left(\phi_{\text {acid }}\right)$ for the sensitization by the pyrromethene dye was much higher than that for the direct excitation of the PAG giving a high sensitivity to the photopolymer. The sensitizer/PAG photoinitiating system was extended in UV light area with an anthracene derivative. The electronic structure of the PAG and the radical anion were estimated by molecular orbital (MO) calculation. The corresponding PAG radical anions give reasonable result for the enhancement of $\phi_{a c i d}$.
\end{abstract}

Keywords: Sensitization, Electron transfer, Pyrromethene dye, Photo-acid generator, Oxime ester

\section{Introduction}

In photochemistry of oximes, $E, Z$-isomerization is well known to give thermally stable $Z$-isomer [1]. $O$-acyloximes and $N$-acyloxyphthalimides decomposed from the $\mathrm{N}-\mathrm{O}$ bond cleavage in high yield in the presence of electron-transfer photosensitizers in solution [2]. The $O$-acyloximes have been known as radical photoinitiators and photo base generators to give primary amines [3]. Some sensitizers were used with $O$-acyloximes as photoinitiating sytems in polymer films. Oxime sulfonates have been investigated as photo acid generators (PAGs) for the 157-nm lithography [4], the ArF dry and immersion lithography [5] and forming color filter or other electronic patterning.

The PAG sensitization system is promising in the field where the radical polymerization has been widely applied such as printing, since the photochemically or photophysically generated acids are not affected by the oxygen in the atmosphere, while the radicals are easily quenched. In this light, we have reported some novel PAG sensitization systems showing extremely high photosensitivity [6-10].

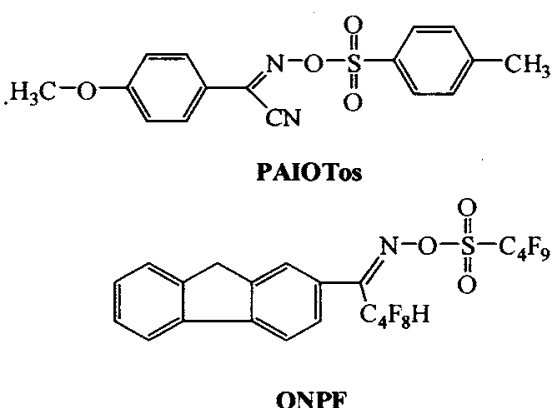

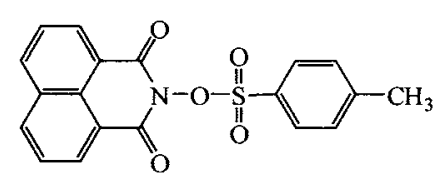

NIOTos<smiles>O=C1C2C3C=CC(C3)C2C(=O)N1OS(=O)(=O)C(F)(F)F</smiles>

NDIOTf

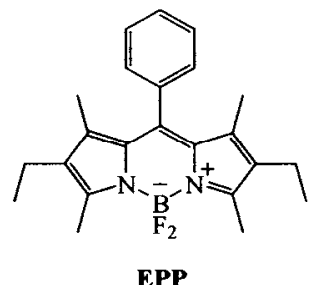

Scheme 1 
In the studies that the pyrromethene sensitizing dye (PYR) has been mainly used, the sensitization mechanism is concluded to the excited singlet electron transfer from the PYR to PAG, which results in the acid generation. The crucial factors affecting the photoacid generation have been investigated further [9-10].

In this paper, we report on a new PYR/oxime type of photoacid generator photoinitiating system to give as high photosensitivity. Moreover, the design of the singlet sensitizer/the oxime derivatives was examined to work in the UV light area with an anthracene derivative. The high photoacid generation quantum yield was discussed from the structure of PAGs' radical anions estimated by a quantum mechanical calculation.

\section{Experiment}

\subsection{Materials}

The pyrromethene derivative, 2,6-diethyl-8-phenyl-1,3,5,7-tetramethylpyrromethene $\quad \mathrm{BF}_{2}$ complex (EPP) was synthesized as described [12]. 9-Methylanthracene (MA, Aldrich) was re-crystallized from methanol.

The oxime type of PAG, $(Z, E)$-2-(4-methoxy-phenyl)-2-[(4-methylphenylsulphonyl)oxyimino]acetonitrile (PAIOTos) was provided by Midori Kagaku, and (Z,E)-2-[2,2,3,3,4,4,5,5,-octafluoro-1-(nonafluorobutylsulfonyloxyimino)-pentyl]-

-fluorene (ONPF) was provided by Ciba Speciality Chemicals. The naphthalimide type of PAG, NIOTos was synthesized according to the well-known procedure $[13,14]$, and $N$-(trifluoro-methanesulfonyloxy)-5-norborene-2,3-dicarbox-imide (NDIOTf) was provided by Midori Kagaku. Their corresponding chemical structures are shown in Scheme 1.

\subsection{Measurements}

Ground state absorption and fluorescence spectra were recorded on a Beckman DU640 spectrophotometer and a Horiba FluoroMax 2 fluorescence spectrophotometer, respectively.

The redox potential measurements, time resolved spectroscopy, and determination of the photoacid generation quantum yield $\left(\phi_{\text {acid }}\right)$ were performed as described in the previous article [10].

\subsection{Molecular Orbital (MO) Calculation}

All quantum mechanical calculations were performed on the GAUSSIAN 98 suite of programs [10]. For the density functional theory (DFT) calculations, (U)B3LYP/6-311++G**// (U)B3LYP/6-31G* level of theory was applied.

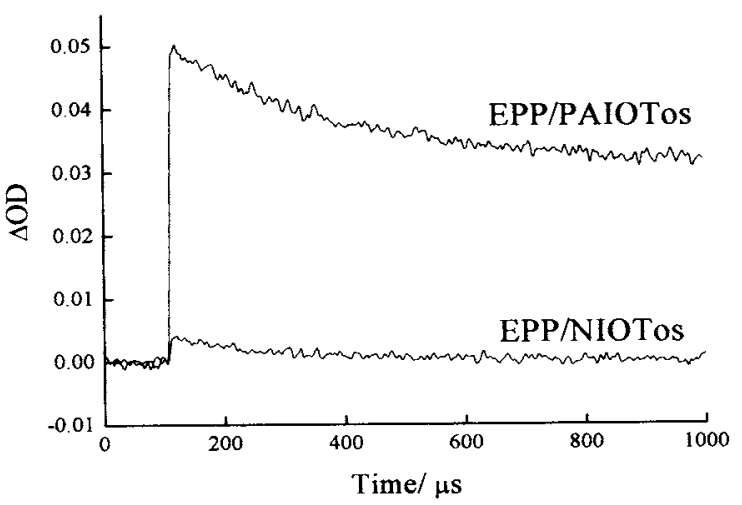

Figure 1. The optical density of EPP radical cation in EPP/PAIOTos and EPP/NIOTos systems monitored at $400 \mathrm{~nm}$ by the time resolved spectroscopy method. $[E P P]=3.11 \times 10^{-5} \mathrm{~mol} / \mathrm{l}$ and $[\mathrm{PAG}]=2.11 \times 10^{-2} \mathrm{~mol} / \mathrm{l}$ in acetonitrile.

Photosensitivity measurement is also as described [6, 16].

\section{Results and Discussion}

\subsection{EPP/Oxime type of PAG}

Table 1 shows the relevant photochemical parameters in the EPP/NIOTos [10] and EPP/PAIOTos systems. The $k_{q}^{S}$ is the singlet quenching rate constant obtained from the quenching of the fluorescence of sensitizer with PAG. The $\phi_{p h}$ is the decomposition quantum yield of sensitizer.

Table 1. Relevant photochemical parameters in the EPP/NIOTos and EPP/PAIOTos systems.

\begin{tabular}{|c|c|c|}
\hline & NIOTos $^{c}$ & PAIOTos \\
\hline $\log k_{q}^{s}$ & 9.96 & 9.45 \\
\hline$\Delta G_{s}{ }^{\mathrm{b}}\left(\mathrm{kcal} \mathrm{mol}^{-1}\right)$ & -6.8 & -3.3 \\
\hline$\phi_{\text {acid }}{ }^{\mathrm{a}}$ & 0.011 & 0.660 \\
\hline$\phi_{p h}^{\mathrm{a}}$ & 0.004 & 0.091 \\
\hline$\Delta H\left(\mathrm{kcal} \mathrm{mol}^{-1}\right)^{\mathrm{d}}$ & -5.01 & -21.6 \\
\hline
\end{tabular}

The negative values of the Gibbs free energy change for the singlet electron transfer, $\Delta G_{S}$ and direct observation of the EPP radical cation, which was observed in the EPP/NIOTos [10] and 
EPP/PAIOTos (Figure 1) systems, enable to conclude that the singlet electron transfer is the main reaction pathway leading to the acid generation. On the contrary, the lack of the triplet state quenching indicates that the reaction from the triplet state is negligibly low.

It is of great interest that the quantum yield of acid generation, $\phi_{\text {acid }}$ value in the EPP/PAIOTos system is higher by far than the EPP/NIOTos system, although both of the PAGs bear the same acid moiety and the $\Delta G_{S}$ and the $k_{q}^{S}$ values for the former is worse than the latter.

The $\Delta H$ is the enthalpy change from the PAG radical anion to corresponding radical and anion (Scheme 2). The values shown in Table 1 were estimated by the DFT calculations.

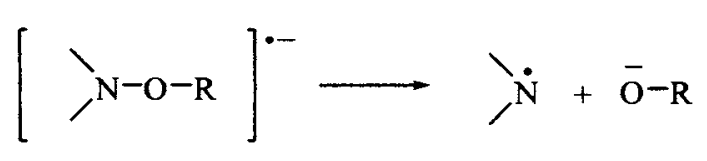

Scheme 2

The value of $\Delta H$ of the PAIOTos reaction is larger negative energy than that of the NIOTos is. It agrees with the higher $\phi_{\text {acid }}$ in the EPP/PAIOTos system.

The sensitization mechanisms in the 9,10-bis(phenylethynyl)-1,8-dimethoxyanthracene (DMBA)/ $N$ - (trifluoromethanesulfonyloxy) -1,8-naphthalimide (NIOTf) system and EPP/NIOTf are also considered to the excited singlet transfer from each dye to NIOTf [6-10]. The photochemical parameters of some singlet sensitizer/sulfonyloxyphthalimides are summarized in Table 2.

Table 2. The relationship among $\Delta G_{S}, \phi_{a c i d}$ and the photosensitivity of the photopolymer in the DMBA/NIOTf (I), EPP/NIOTos (II) and EPP/NDIOTf (III) systems.

\begin{tabular}{lccl}
\hline & I & II & III \\
\hline$\Delta G_{s}\left(\mathrm{kcal} \mathrm{mol}^{-1}\right)$ & -21.3 & $-6.8^{\mathrm{d}}$ & 10.9 \\
$\phi_{\text {acid }^{\mathrm{a}}}$ & 0.072 & $0.011^{\mathrm{d}}$ & $<0.001$ \\
$\begin{array}{c}\text { Photosensitivity } \\
\text { ( }\end{array}$ & 0.12 & 0.32 & $-{ }^{\mathrm{c}}$ \\
\hline $\left.\mathrm{mJ} \mathrm{cm}^{-2}\right)$ & & & \\
\hline
\end{tabular}

${ }^{a}$ Corrected for $100 \%$ fluorescence quenching. ${ }^{b}$ Measured under the photopolymer film to have same absorbance at the excitation wavelength (488 nm). ${ }^{c}$ Upper limit: $1.5 \mathrm{~J} \mathrm{~cm}^{-2}$. ${ }^{d}$ From [10].
The $\Delta G_{S}$ in the DMBA/NIOTf and EPP/NIOTf system are negative. The $\Delta G_{S}$ in the EPP/NDIOTf is positive. The $\phi_{\text {acid }}$ of DMBA/NIOTf in the present study is 0.072 . The $\phi_{\text {acid }}$ of EPP/NIOTf is 0.011 [10]. NDIOTf is the PAG showing high $\phi_{\text {acid }}$ (0.55) [17] by direct excitation, however its sensitization by EPP does not yield the acids $(<0.001)$.

The photosensitivities of the photopolymer with the DMBA/NIOTf and EPP/NIOTf systems were 0.12 and $0.32 \mathrm{~mJ} \mathrm{~cm}^{-2}$. That of EPP/NIOTf system could not be obtained in the experiment. There exists a clear correlation between photosensitivity, $\phi_{a c i d}$ and $\Delta G_{S}$.

In the case of the direct excitation of PAIOTos at $355 \mathrm{~nm}$, the value of 0.09 is obtained as $\phi_{\text {acid }}$. This means the sensitization of PAIOTos is much more effective than the direct excitation. The $\phi_{\text {acid }}$ value, 0.660 is also higher than both the direct excitation of NIOTf $(0.18$ [10]) and its sensitization by EPP or DMBA (Table 2).

Figure 1 shows the decay of optical density of the EPP radical cation in each system in solution monitored at $400 \mathrm{~nm}$ by the ns-laser flash photolysis. The optical density of the intermediate in the EPP/PAIOTos system is ca 10 times higher than the EPP/NIOTos system. It indicates that the rate of the back electron transfer in the former is much lower and the $\mathrm{N}-\mathrm{O}$ bond cleavage of PAIOTos radical anion occurs efficiently.

Table 3. Photochemical parameters in the MA/ONPF and MA/PAIOTos systems.

\begin{tabular}{|c|c|c|}
\hline & ONPF & PAIOTOS \\
\hline $\log k_{q}^{s}$ & 9.94 & 10.2 \\
\hline$\Delta G_{s}{ }^{\mathrm{b}}\left(\mathrm{kcal} \mathrm{mol}^{-1}\right)$ & -27.6 & -22.8 \\
\hline$\phi_{\text {acid }}{ }^{\mathrm{a}}$ & $(0.089)^{c}$ & 0.176 \\
\hline$\phi_{\text {acid (direct) }}$ & $(0.761)^{c}$ & 0.090 \\
\hline \multicolumn{3}{|c|}{$\begin{array}{l}\text { a Corrected for } 100 \% \text { fluorescence quenching. }{ }^{b} E_{\text {red }} \text { of ONPF is }-0.85 \\
\text { V/SCE. }{ }^{c} \text { Extrapolated on the analytical curve of } p \text {-toluenesulfonic acid. }\end{array}$} \\
\hline \multicolumn{3}{|c|}{$\begin{array}{l}\text { 3.2. MA/Oxime type of PAG } \\
\text { Methylanthracene (MA) works as a singlet } \\
\text { sensitizer and it has the absorption in UV light } \\
\text { region. The MA/PAIOTos system also shows } \\
\text { higher } \phi_{\text {acid, }} 0.176 \text { than that of direct excitation. } \\
\text { However, in the case of MA/ONPF system the } \phi_{\text {acid }} \\
\text { is lower than that of direct excitation. In other }\end{array}$} \\
\hline
\end{tabular}



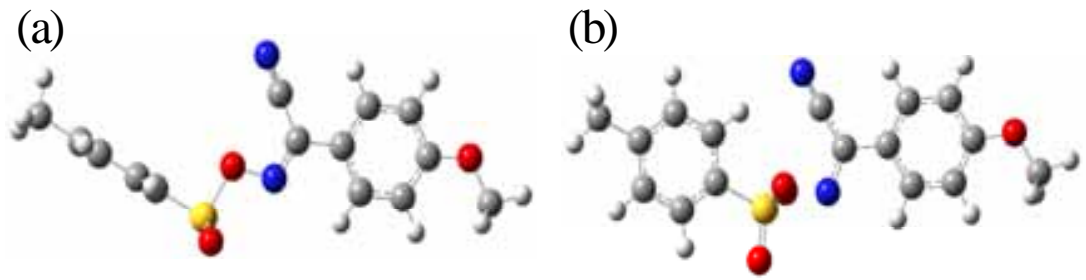

Figure 2. Geometries of the (a) ground state and (b) radical anion for PAIOTos.

very large and it is about ten times of the MA/ONPF, though we could not obtain the absolute value. The results are shown in Table 3.

The MA/PAIOTos system and direct excitation of PAIOTos gave 0.83 and $14.60 \mathrm{~mJ} \mathrm{~cm}^{-2}$ in the sensitivity of the photopolymer. The sensitization enhanced the $\phi_{\text {acid }}$ and sensitivity. It is the other way around in the case of MA/ONPF and ONPF. Their sensitivities were 9.62 and $7.90 \mathrm{~mJ} \mathrm{~cm}^{-2}$, respectively, and a large difference was not observed between them.

\subsection{Molecular modeling}

Figure 2 shows the geometries of the ground state (GS) and radical anion (RA) for PAIOTos. The N-O bond length changes from $1.39 \AA$ (GS) to $1.48 \AA$ (RA) and a $p$-toluenesulfonyl group rotates at an angle of ca $73^{\circ}$ in the RA, while no significant change is observed in the case of NIOTos. Then, the spin density was calculated as is shown in Figure 3. It is worth noting that the localization of the spin is totally different in two PAGs. The spin density in PAIOTos is mainly localized around the $\mathrm{N}-\mathrm{O}$ bond, while it is localized around the naphthalene chromophore in the case of NIOTos as is already reported for other naphthalimide derivatives in the previous study [11]. Especially, the nitrogen atom in $\mathrm{N}-\mathrm{O}$ bond possesses the highest density in PAIOTos. It can account for the change in the geometry, namely, the radical originated from the singlet electron transfer is localized at the weakest $\mathrm{N}-\mathrm{O}$ bond, which induces the change in the $\mathrm{N}-\mathrm{O}$ bond length and its rotation. This should be deeply involved in the reason for high $\phi_{\text {acid }}$.

Assuming the following type of $\mathrm{N}-\mathrm{O}$ bond cleavage process (Scheme 2) in both PAGs, the enthalpy change, $\Delta H$ can be calculated as is collected in Table 1. Indeed, even the acid moiety is the same; the exergonicity of the cleavage process for PAIOTos is higher than that for NIOTos.

Summarizing the above discussion, it is considered that the spin localization of the RA is a crucial factor affecting the photoacid generation. The efficiency of the singlet electron transfer is also very important, however if a certain amount of RA is formed, then the $\phi_{a c i d}$ is mainly subject to the spin localization of the RA. For example, although the $\Delta G_{S}$ value for the DMBA/NIOTf system is much higher than that for the EPP/PAIOTos system, the fragility of the NIOTf radical anion is not high due to the fact that the radical is mainly localized around the naphthalene chromophore, which is not involved in the $\mathrm{N}-\mathrm{O}$ bond cleavage process. As a consequence, $\phi_{\text {acid }}$ shows a very low value; even the PAG can yield the strong acids. In the case of ONPF, it is also considered that the radical spin is localized around fluorene moiety in the radical anion, giving no enhancement of the acid generation. (a)

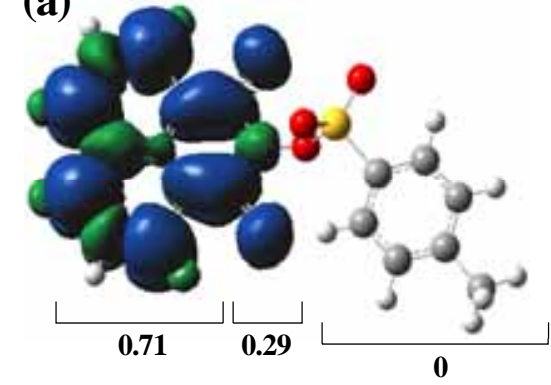

(b)

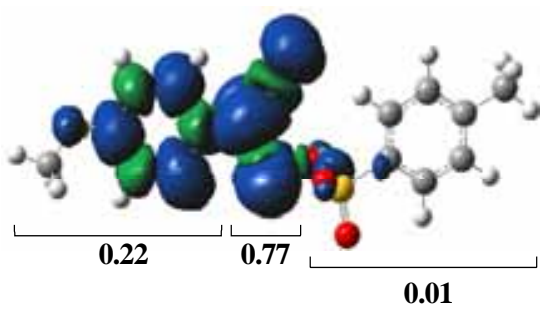

Figure 3. Spin density for each radical anion: (a) NIOTos; (b) PAIOTos, along with the sum of the spin density for the corresponding part. 
around the naphthalene chromophore, which is not involved in the $\mathrm{N}-\mathrm{O}$ bond cleavage process. As a consequence, $\phi_{\text {acid }}$ shows a very low value; even the PAG can yield the strong acids. In the case of ONPF, it is also considered that the radical spin is localized around fluorene moiety in the radical anion, giving no enhancement of the acid generation.

On the other hand, the EPP/PAIOTos system possessing a moderately negative $\Delta G$ value shows extremely high photoacid generation efficiency due to its specific radical localization. It is possible to apply the mechanism to other sensitizer/PAIOTos system to generate the radical anion of PAG.

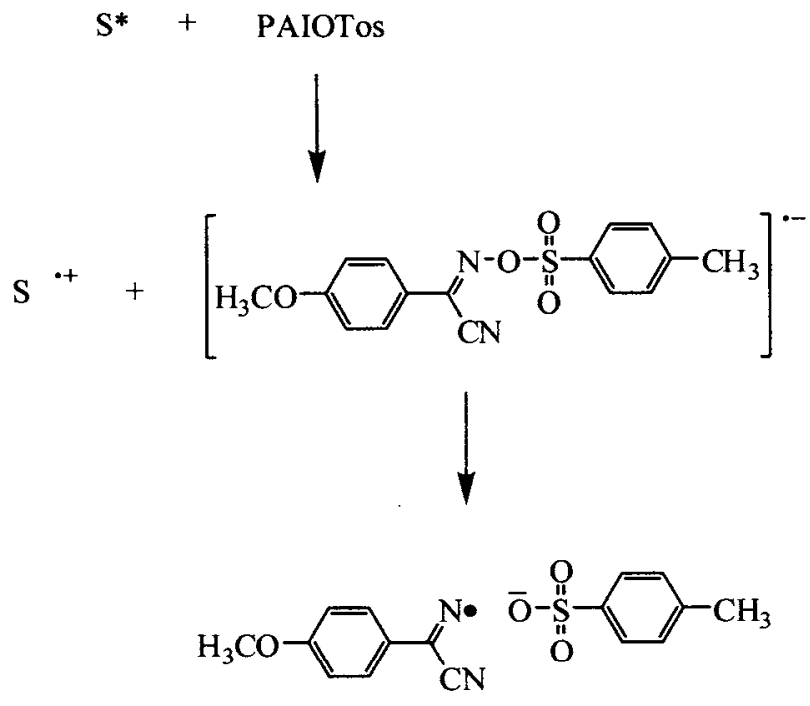

Scheme 3

As far as the cleavage mechanism is concerned, Scheme 3 is considered to the main pathway leading to the acid generation, while it is the $\mathrm{N}-\mathrm{O}$ bond homolytic cleavage in the case of the direct excitation. The recombination of the two nitrogen centered radicals was also observed in the present system, as well as that reported.

The photosensitivity obtained from EPP/PAIOTos system, together with an appropriate binder polymer bearing the acid protection group $[6,10]$, is $18 \mu \mathrm{J} \mathrm{cm}$ at maximum so far, which is extremely high and compete with the conventional radical polymerization system.

\section{Conclusions}

The design signpost in the PAG sensitization system based on the singlet transfer is considered as follows, 1) the efficiency of singlet transfer, 2) the spin localization of the PAG radical anion, 3) acid strength, 4) proton donor.
As for the proton donor, it is better to be contained always in the system. The first two factors play a crucial role and $\Delta G, \Delta H$, and spin density can be the representatives to evaluate them. Above all, the estimation of the $\Delta G$ value should be the first step. Once the formation of radical anion is suggested from $\Delta G$, then it is necessary to see its $\Delta H$ and spin density at the intended cleavable part such as $\mathrm{N}-\mathrm{O}$ bond.

As is discussed above, the spin localization of the radical anion is significantly dependent on the basic structure and there exists a good correlation between $\phi_{a c i d}, \Delta H$, and spin density. The results of the EPP/PAIOTos system suggest that the strong acids are not always required, if the better basic structure like the PAIOTos radical anion possesses is found. As for the information on the acid strength, it is also involved in the enthalpy change from the PAG radical anion to corresponding radical and anion, $\Delta H$, therefore, the ab initio calculation of $\Delta H$ and spin density is really valuable to predict and design the better PAG sensitization system.

\section{References}

[1] W. Horspool, D. Armesto, Organic Photochemistry: A Comrehensive Treatment, Ellis Horwood, West Sussex (1992) p355.

[2] J. Kopckỳ, Organic Photochemistry: A Visual approach, VCH publishers, New York (1992) p164.

[3] J. V. Crivello and K. Dietliker, Photoinitiators for Free Radical, Cationic and Anionic Photopolymerization, $2^{\text {nd }}$ Edition, G. Bradley Ed.,Wiley and Sons, New York (1988) p494.

[4] T. Hagiwara, S. Irie, T. Itani, Y. Kawaguchi, O. Yokokoji, S. Kodama, J. Photopolym. Sci. Tech., 16 (2003) 557.

[5] T. Asakura, H. Yamato, T. Itani, Y. Nishimae, M. Owwa, J. Photopolym. Sci. Tech., 20 (2007) 465.

[6] S. Suzuki, T. Urano, K. Ito, T. Murayama, I. Hotta, S. Takahara, T. Yamaoka, J. Photopolym. Sci. Tech., 17 (2004) 125.

[7] S. Noppakundilograt, S. Suzuki, T. Urano, N. Miyagawa, S. Takahara, T. Yamaoka, Polym. Adv. Technol., 13 (2002) 527.

[8] J. Iwaki, S. Suzuki, C. Park, N. Miyagawa, S. Takahara, T. Yamaoka, J. Photopolym. Sci. Tech., 17 (2004) 123.

[9] S. Suzuki, J. Iwaki, T. Urano, S. Takahara, T. Yamaoka, Polym. Adv. Technol., 17 (2006) 348.

[10] S. Suzuki, X. Allonas, J. P. Fouassier, T. Urano, S. Takahara, T. Yamaoka, J. Photochem. Photobiol. A: Chem., 181 (2006) 60. 
[11] J. P. Malval, F. Morlet-Savary, X. Allonas, J. P. Fouassier, S. Suzuki, S. Takahara, T. Yamaoka, Chem. Phys. Lett., 443 (2007) 323.

[12] I. García-Moreno, A. Costela, L. Campo, R. Sastre, F. Amat-Guerri, M. Liras, F. López Arbeloa, J. Bañuelos Prieto, I. López Arbeloa, J. Phys. Chem. A., 108 (2004) 3315.

[13] C. Iwashima, G. Imai, H. Okamura, M. Tsunooka, M. Shirai. J Photopolym. Sci. Tech., 16 (2003) 91.
[14] M. Narita, T. Teramoto, M. Okawara, Bull. Chem. Soc. Jpn., 44 (1971) 1084.

[15] M. J. Frisch, et al., Gaussian Inc, Pittsburg PA, 1998.

[16] S. Suzuki, P. Emilie, T. Urano, S. Takahara, T. Yamaoka, Polymer, 46 (2005) 2238.

[17] K. Ray, M. D. Mason, R. D. Grober, G. Pohlers, C. Staford, J. F. Cameron, Chem. Mater., 16 (2004) 5726. 